\title{
Lymphocytic adenosine deaminase activity in typhoid fevers
}

\author{
S.N. Khosla, Dinesh Kumar and V. Singh \\ Medical College and Hospital, Rohtak, Haryana, India
}

\begin{abstract}
Summary: Lymphocyte adenosine deaminase (L-ADA) activity, a measure of lymphocyte activity, was estimated in 10 healthy controls and 30 patients with typhoid fever (20 uncomplicated and 10 complicated) at the time of admission, at onset of complications and weekly until recovery. Mean L-ADA activity in healthy controls was $20.49 \pm 3.62 \mathrm{mU} / 10^{6}$ cells. In uncomplicated patients L-ADA activity was $36.33 \pm 5.09 \mathrm{mU} / 10^{6}$ cells at time of admission, which is significantly raised as compared to controls. It remained high at the height of the fever and at defervescence. In complicated patients L-ADA activity was significantly low at admission $\left(15.33 \pm 2.35 \mathrm{mU} / 10^{6}\right.$ cells) and fell further with development of complications $\left(7.86 \pm 4.07 \mathrm{mU} / 10^{6}\right.$ cells). At defervescence $\mathrm{L}$-ADA activity increased significantly above the control activity (31.24 \pm 5.37$)$.

Serial L-ADA activity can be of prognostic significance. A cut-off value of $24 \mathrm{mU} / 10^{6}$ cells is suggested to predict prognosis and severity of disease. Activity below this indicates a probability of a severe, prolonged course and may help in instituting early and energetic treatment.
\end{abstract}

\section{Introduction}

Adenosine deaminase (ADA) is an enzyme of purine metabolism that catalyses the deamination of adenosine to inosine. It it widely distributed in human tissues and shows its highest activity in lymphoid tissues, particularly those containing the highest proportions of T-cells. ${ }^{1}$ A relationship between lymphocyte ADA (L-ADA) activity and the immune response was shown by the discovery of inherited ADA deficiency which causes severe combined immune deficiency (SCID) ${ }^{2-4}$ ADA is required for proliferation and differentiation of T-lymphocytes, and its deficiency mainly affects T-cell activation and cell-mediated immunity. ${ }^{5-7}$ Activation of lymphocytes produces an increase in intracellular ADA levels. ${ }^{5}$ High L-ADA activity has been observed in tuberculosis and in subjects with renal allograft transplants undergoing acute graft rejection where cell-mediated immunity is stimulated. ${ }^{8,9}$ In contrast, low levels of L-ADA activity have been found in patients with diseases which suppress immune responses, such as solid tumours, chronic active hepatitis and chronic renal failure. ${ }^{10,11}$

Cell-mediated immunity plays a major role in recovery from typhoid fever which is still endemic in India and is a major cause of mortality and morbidity. ${ }^{12}$ Cell-mediated immunity develops

Correspondence: S.N. Khosla, M.D., F.I.A.M.S., Professor of Medicine, 18/8 FM, Medical Enclave, Medical College, Rohtak-124001, Haryana, India. Accepted: 22 October 1991 during the second week of illness in uncomplicatedo $\notin$ patients, while it is often impaired and delayed ins patients who develop complications. ${ }^{13,14}$ Patientso who relapse also have poor cell-mediated immunity. ${ }^{15}$

Since a relationship exists between ADA activity and the cell-mediated immune response, this study was undertaken to evaluate L-ADA activity in patients with typhoid fever and to correlate this with the clinical profile and prognosis.

\section{Materials and methods}

Thirty adult patients with typhoid fever were studied comprising 23 male and 7 females, their ages ranging from 15 to 40 years. All were diagnosed by a positive blood or bone marrow culture for Salmonella typhi/paratyphi and/or fourfold rise in Widal titres. Patients who were on corticosteroids, received TAB vaccine during the last 5 years, and patients with cirrhosis, tuberculosis, leukaemias, or tumours where altered ADA activity is known were excluded. All patients underwent a detailed history, physical examination and were observed carefully during hospitalization; they were followed up for one month after recovery. Haemoglobin, total and differential counts, ESR, complete urine examination, stool for occult blood, blood urea, blood sugar, serum electrolytes, serum transaminases, serum bilirubin, chest X-ray and electrocardiogram were done in all patients at the time of admission and then serially. 
Non-specific cell-mediated immunity was studied in all patients by observing cutaneous delayed hypersensitivity responses to dinitrochlorobenzene (DNCB) as described by Catalona et al. ${ }^{16}$ The response was graded as follows. (a) Grade $4+$ (four plus) if spontaneous flare occurred at both sites of DNCB application within first 14 days. (b) Grade $3+$ (three plus) if spontaneous flare occurred only at the site of $2,000 \mu \mathrm{g}$ DNCB application. In case of failure to get a spontaneous flare within the first 14 days at either site, a challenge dose of $50 \mu \mathrm{g}$ DNCB was reapplied and reaction was observed up to $72 \mathrm{~h}$ and graded as follows. (c) Grade $2+$ (two plus) if unequivocal spontaneous flare occurred. (d) Grade $1+$ (one plus) if reaction was equivocal. (e) Negative response $(-)$ if no response occurred.

\section{Estimation of lymphocytic adenosine deaminase activity}

Lymphocytes were separated by the method of Boyum $^{17}$ and L-ADA activity was estimated by the method of Guisti, ${ }^{18}$ in all patients with typhoid fever at the time of admission, during the height of fever in the acute phase, at the time of development of complications and subsequently at weekly intervals till recovery.

The results were statistically analysed using Student's $t$-test and $\chi^{2}$ (chi-square) test.

\section{Results}

All patients were admitted with a history of fever of 3-12 days duration. They were divided into 2 groups depending on presence or absence of complications. Out of the total of 30 patients, 20 patients $(66.6 \%)$ were uncomplicated, while 10 patients $(33.3 \%)$ had a complicated course. Four patients developed complications after the hospitalization, while 6 patients were admitted with complications of typhoid fever. Seven patients had various types of neuropsychiatric complications (encephalopathy, 4; schizophrenia, 1 ; cerebellitis, 1 ; meningismus, 1 ). One of these patients also developed peripheral circulatory failure. Two patients presented with intestinal perforation and one patient presented with intestinal haemorrhage. All the patients recovered after treatment and there was no mortality.

The age of patients ranged from $15-40$ years and the mean age in the 2 groups was not statistically different. Males and females were affected in a ratio of 3.3:1. All the patients were treated with chloramphencol or ampicillin or a combination of both drugs. The complicated group of patients took a significantly longer time $(P=0.01)$ to reach the stage of defervescence as compared to uncomplic- ated patients. Complicated patients also had a significantly lower haemoglobin $(P=0.05)$ as compared to uncomplicated patients. Blood sugar, blood urea, serum electrolytes, serum transaminases, serum bilirubin, chest X-ray and electrocardiograms were within the normal range in all patients.

\section{Cutaneous delayed hypersensitivity response to DNCB (Table I)}

All the uncomplicated patients were good reactors (Grade $4+$ and $3+$ ) to DNCB, while the majority of the patients showed weaker responses.

The difference between the 2 groups was significant, $P<0.001$ ( $\chi^{2}$ test). Thus there was unequivocal depression in delayed cutaneous hypersensitivity response to DNCB in the complicated group.

\section{Lymphocytic adenosine deaminase activity (Table II, Figure 1)}

(A) Controls L-ADA activity in controls ranged from $15.6-25.6 \mathrm{mu} / 10^{6}$ cells (means \pm s.d. $=$ $20.49 \pm 3.62)$.

(B) Uncomplicated patients At the time of admis sion L-ADA activity in uncomplicated patients was significantly higher than the control activity $(P<0.001)$. L-ADA activity increased further dur ing the height of fever and at the time of recovery?

(C) Complicated patients In patients who later developed complications, L-ADA activity was significantly less than control activity at the time of admission $(P<0.05)$. Mean L-ADA activity decreased still further at the time of development of complications $(P<0.001)$. At the time of recovery L-ADA activity increased significantly above the control activity $(P<0.01)$.

All the patients who had L-ADA activity above $24 \mathrm{mU} / 10^{6}$ cells at the time of admission and during the height of fever remained uncomplicated, while patients with L-ADA activity below $24 \mathrm{mU} / 10^{6}$ cells presented either with complications or developed complications during hospitalization. On serial estimation, an increase in L-ADA activity

Table I DNCB response in complicated and uncomplicated patients

\begin{tabular}{lccccc}
\hline & $(4+)$ & $(3+)(2+)$ & $(1+)$ & $(-)$ \\
\hline $\begin{array}{c}\text { Uncomplicated } \\
(n=20)\end{array}$ & 17 & 3 & - & - & - \\
$\begin{array}{c}\text { Complicated } \\
(n=10)\end{array}$ & 1 & 2 & 5 & 2 & - \\
\hline
\end{tabular}


Table II L-ADA activity in typhoid fever ( $\mathrm{mU} / 10^{6}$ cells)

\begin{tabular}{|c|c|c|c|}
\hline & $\begin{array}{c}\text { At } \\
\text { admission }\end{array}$ & $\begin{array}{c}\text { Height of } \\
\text { fever/onset of } \\
\text { complication }\end{array}$ & Defervescence \\
\hline $\begin{array}{l}\text { Uncomplicated } \\
\text { mean } \pm \text { s.d. } \\
\text { range }\end{array}$ & $\begin{array}{c}36.33 \pm 5.09^{*} \\
31.2-45.6\end{array}$ & $\begin{array}{l}41.12 \pm 8.88^{*} \\
31.2-62.5\end{array}$ & $\begin{array}{c}43.85 \pm 9.09^{*} \\
33.2-68.7\end{array}$ \\
\hline $\begin{array}{l}\text { Complicated } \\
\text { mean } \pm \text { s.d. } \\
\text { range }\end{array}$ & $\begin{array}{c}15.33 \pm 2.35^{* *} \\
12.5-17.8\end{array}$ & $\begin{array}{l}7.86 \pm 4.07^{*} \\
2.5-14.4\end{array}$ & $\begin{array}{c}31.24 \pm 5.37^{* * *} \\
24.9-37.5\end{array}$ \\
\hline
\end{tabular}

" $P<0.001 ;{ }^{* *} P<0.05 ;{ }^{* * *} P<0.01$; as compared to control activity $(20.49 \pm 3.62)$.

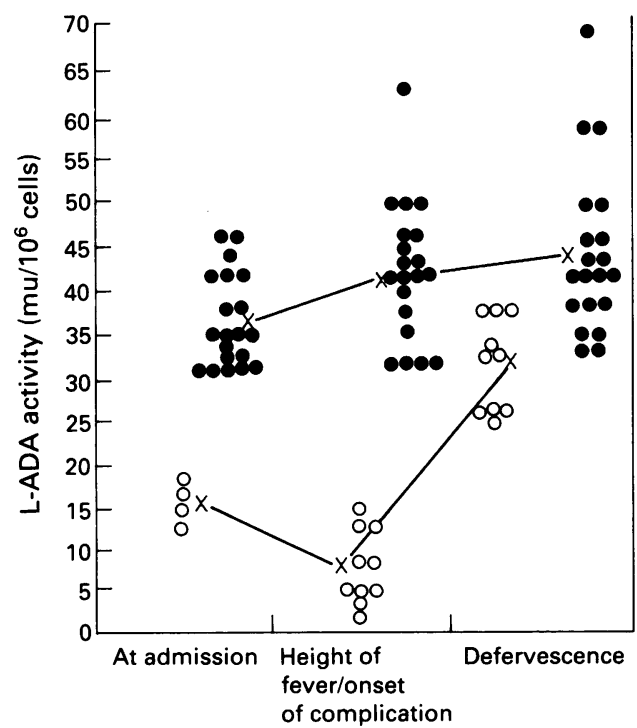

Figure 1 L-ADA activity in the uncomplicated and complicated groups of typhoid patients. Of the complicated patients, 4 developed complications during the course of their illness in hospital while 6 had complications at the time of admission.

above $24 \mathrm{mU} / 10^{6}$ cells was associated with recovery in complicated patients.

\section{Correlation between $D N C B$ response and $L-A D A$ activity}

Uncomplicated patients demonstrated a good response to DNCB and had significantly higher normal L-ADA activities during the acute stage of illness. In contrast complicated patients had a poor response to DNCB and significantly lower L-ADA activity during the acute stage of illness.
Statistical correlation between DNCB response and L-ADA activity was highly significant (coefficient of correlation $r=0.0690, P<0.001$ ). All the patients were treated with ampicillin, and/or chloramphenicol and there was no association between the drugs given and L-ADA levels or DNCB responses.

\section{Discussion}

Typhoid fever is a major cause of morbidity and mortality in India. There are many methods for diagnosing the disease, but there are very few parameters by which the severity and prognosis can be predicted. We have previously demonstrated that persistence of extrapyramidal rigidity and electrocardiographic abnormalities, including arrythmias, indicate a poor prognosis. ${ }^{19,20}$ Since recovery from typhoid fever is associated with development of cell-mediated immunity, and patients with complications have a poor or delayed cell-mediated immune response, an indirect indicator of $T$ cell activity such as L-ADA activity could be prognostically useful.

From our observations it is clear that serial estimation of L-ADA activity is a good indicator of severity and prognosis in patients with typhoid fever. Mean L-ADA activity was significantly raised $(36.33 \pm 5.09)$ in uncomplicated patients at the time of admission and remained so even at the time of defervescence. Similar findings have been reported by others. ${ }^{21,22}$

On the other hand, mean L-ADA activity in patients who developed complications was significantly low at the time of admission (15.33 \pm 2.35$)$ and fell further at the onset of complications $(7.86 \pm 4.07)$. However, with recovery, L-ADA activity increased significantly above the control activity (31.24 \pm 5.37$)$.

To predict the severity and prognosis in typhoid fever a cut-off value of $24 \mathrm{mU} / 10^{6}$ cells could be 
used, since all the patients with activity above this level remained uncomplicated. Patients with activity below this level developed various complications and had a prolonged course. The mechanism of alteration in L-ADA activity in different groups of typhoid patients can be explained on the basis of its relation to $\mathrm{T}$-cell activity. This may be a direct or indirect result of severe endotoxaemia since lipopolysaccharide of Gram-negative bacteria is known to have a suppressive effect on T-cell activity. ${ }^{23.24}$

Low levels of ADA are an indication that treatment should be instituted more energetically. Since in patients with typhoid with severe endotoxaemia and/or complications, CMI is suppressed, an appropriate line of treatment should be the admini- stration of antibody against lipopolysaccharide of Gram-negative bacteria. Since no such therapeutics are available, a combined drug therapy with steroids should be employed. We have already demonstrated ${ }^{25}$ that cases of typhoid having severe toxaemia have depression of adrenocortical function and should be given supplementary steroids, if no contraindications exist.

L-ADA estimation is simple and its serial activity can be used as a good indicator to assess severity of disease process and prognosis. However since our study involved only a small number of patients, a larger study is needed to clearly establish a use for L-ADA activity levels in the management of typhoid fever.

\section{References}

1. Barton, R., Martiniuk, F., Hirschhorn, R. \& Goldschneider, G. The distribution of adenosine deaminase among lymphocyte population in rat. $J$ Immunol 1979, 122: 216-220.

2. Dissing, J. \& Knudsen, B. Adenosine deaminase deficiency and combined immunodeficiency syndrome. Lancet 1972, 2: 1316.

3. Giblett, E.R., Anderson, J.E. \& Cohen, F. Adenosine deaminase deficiency in two patients with severely impaired cellular immunity. Lancet 1972, 2: 1067.

4. Parkman, R., Gelfond, E.W., Rosen, F.S., Sanderson, A. \& Hirschhorn, R. Severe combined immunodeficiency and adenosine deaminase deficiency. $N$ Engl $J$ Med 1975, 292: 714.

5. Hovi, T., Smyth, J.E., Allison, A.C. \& Williams, S.C. Role of adenosine deaminase in lymphocytic proliferation. Clin Exp Immunol 1976, 23: 395.

6. Shore, A., Dosche, M.M. \& Gelfand, E.M. Role of adenosine deaminase in early stages of precursor of T-cell maturation. Clin Exp Immunol 1981, 44: 152-155.

7. Carson, D.M., Kaye, J., Matsumoto, S., Seegmiller, J.E. \& Thompson, L. Biochemical basis for the enhanced toxicity of deoxyribonucleosides towards malignant human T cells lines. Proc Natl Acad Sci USA 1979, 76: 2430.

8. Ocana, I., Jose, M., Martinaz-Vazquez, Ross, M., Fernandez, T. \& Capdevilla, J.A. Adenosine deaminase in pleural fluids, test for diagnosis of pleural fluids. Chest 1983, 84: 51-53.

9. Yasmineh, W.G., Brynes, R.K., Lum, C.T. \& Abbasnezhad, $M$. Adenosine deaminase in lymphocytes of normal persons, leukemic patients and kidney transplant recipients. Clin Chem 1977, 23: 2024.

10. Uberti, J., Johnson, R.M., Talley, R. \& Lighbody, J.J. Decreased lymphocyte adenosine deaminase activity in tumor patients. Cancer Res 1976, 36: 2046.

11. Nardiello, S., Pizzella, T., Tarantino, L., Russo, M. \& Galanti, B. Lymphocytic adenosine deaminase in levels in active and in active forms of $\mathrm{HBsAg}$ positive chronic liver disease. Adv Exp Med Biol 1984, 165 (pt A): 305-308.

12. Khosla, S.N. Changing patterns of typhoid. Asian Med J 1982, 25: $185-196$.
13. Sarma, V.N.B., Malviya, A.N., Kumar, R., Ghai, Op \& Bakhtary, N.M. Development of immune response during typhoid fever of man. Clin Exp Immunol 1977, 28: 35-39.

14. Rajagopalan, P., Kumar, R. \& Malviya, A.N. Immunological studies in typhoid, cell mediated immune responses and lymphocytic subpopulations in patients with typhoid. Clin Exp Immunol 1982, 47: 269-274.

15. Marbal, C.J. \& Pankker, C.K.J. Role of cell mediated immunity in typhoid. Asian J Infect Dis 1979, 3: 69-75.

16. Catalona, W.N., Taylor, P.T., Rabson, A.S. \& Chartien, P.B. A method for DNCB contact sensitization - a clinicopatho logical study. N Engl J Med 1972, 286: 399.

17. Boyum, A. Separation of leucocytes from blood and bone marrow. Scand J Clin Lab Invest 1968, 21 (Suppl 97): 77-89.

18. Glusti, G. Adenosine deaminase. Meth Enz Anal 1974, 2 1092-1099.

19. Khosla, S.N., Srivastav, S.C. \& Gupta, S. Neuropsychiatric manifestations of typhoid. J Trop Med Hyg 1977, 80: 95-98.

20. Khosla, S.N. Heart in enteric. J Trop Med Hyg 1981, 84 125-131.

21. Galanti, B., Nardiello, S., Russo, M. \& Fiorentino, F Increased lymphocyte adenosine deaminase in typhoid fever Scand J Infect Dis 1981, 13: 47-50.

22. Russo, M., Pizzella, T., Nardiello, S., Fiorentino, F. \& Galanti, R. T-cell activation in typhoid detected by increased levels of adenosine deaminase. Adv Exp Med Biol 1984, 165 253-256.

23. Uchiyama, T. \& Jacobs, D.M. Modulation of immune response by bacterial lipopolysaccharide (LPS): multiple effects of LPS-induced suppression to a T-dependent antigen $J$ Immunol 1978, 121: 2340-2346.

24. Motta, I., Partnoi, D. \& Truff Bachi, P. Effect of lipopolysaccharide on lactin induced T-cell activation. Cell Immunol 1986, 97: 267-275.

25. Khosla, S.N., Kalra, I.J. \& Sharma, A. Plasma cortisol levels in enteric fever. $J$ Ass Physicians India 1989, 37: 643-645. 